\title{
Perbandingan Konfigurasi Wenner Alfa, Wenner- Schlumberger, Dipol-dipol Dan Pol-dipol Dalam Metode Geolistrik Tahanan Jenis Untuk Mendeteksi Keberadaan Air Tanah
}

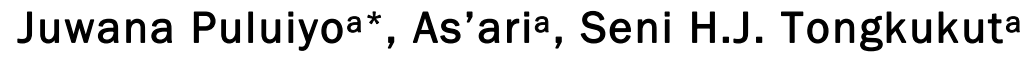 \\ aJurusan Fisika, FMIPA, Unsrat, Manado
}

KATA KUNCI

Geolistrik, Wenner Alfa, Wenner-Schlumberger, Dipoldipol dan Pol-dipol

\begin{abstract}
A B S T R A K
Telah dilakukan penelitian untuk mencari konfigurasi yang paling tepat dalam eksplorasi sumber daya air (air tanah) dengan metode geolistrik tahanan jenis konfigurasi Wenner Alfa, Wenner-Schlumberger, Dipol-dipol dan Pol-dipol menggunakan Resistivity meter (multichannel and multielectrode resistivity and IP meter simultaneous channel merek MAE X612-EM). Pengukuran dilakukuan pada 4 lintasan dengan panjang bentangan 96 meter dan pengolahan data menggunggunakan perangkat lunak (softwere) RES2DINV. Hasil penelitian ini menunjukkan bahwa konfigurasi Dipol-dipol adalah konfigurasi yang paling efektif dan efisien dalam mendeteksi keberadaan air tanah dengan karakteristik : waktu eksekusi 24 menit, jumlah data 609 buah, kedalaman 16 meter dan jumlah data pereksekusi 5 titik..
\end{abstract}

K E Y W O R D

Geoelectrical,WennerAlfa,We nner-Schlumberger,Dipoldipol and Pol-dipol

\begin{abstract}
A B S T R A C T
Research has been done to find the most appropriate configuration in the exploration of water resources (groundwater) with the geoelectrical Resistivity method of configuration Wenner Alfa, Wenner-Schlumberger, Dipole-dipole and Pole-dipole by using Resistivitymeter (multichannel and multielectric resistivity and IP meter simultaneous channel brand MAE X612-EM). Measurements were performed on 4 line with a stretch length of 96 meters and data processing used software RES2DINV.The results of this study indicate that Dipole-dipole configuration is the most effective and efficient configuration in detecting the presence of groundwater with the characteristics : 24 minutes execution time, 609 pieces of data, 16 meters depth and 5 points of execution data.
\end{abstract}

\begin{tabular}{l}
\hline TERSEDIA ONLINE \\
\hline 01 Februari 2018 \\
\hline
\end{tabular}

\section{Pendahuluan}

Air merupakan salah satu kebutuhan utama dari makhluk hidup. Seiring pertambahan jumlah penduduk kebutuhan air juga akan meningkat. Sumber air utama yang banyak dimanfaatkan oleh masyarakat untuk memenuhi berbagai kebutuhan adalah air permukaan seperti sungai, air PAM dari sumur gali dan air tanah seperti sumur bor. Air tanah terdapat didalam akuifer yaitu lapisan tanah yang mengandung air. Akuifer sendiri untuk setiap daerah memiliki kedalaman yang berbeda- bedatergantung pada ketebalan lapisan penutup dan kedudukan akuifernya ( Enggarwati et al., 2014)[4].

Potensi keberadaan air tanah dapat diketahui dengan mengidentifikasi formasi batuan dan struktur bawah permukaan berdasarkan variasi nilai resistivitas dengan menggunakan metode geolistrik (Wijaya, 2015). Metode geolistrik merupakan salah satu metode geofisika yang dapat mengetahui sifat aliran listrik dengan cara mengijeksikan arus kedalam permukaan bumi berdasarkan hukumhukum kelistrikan. Pengukuran beda potensial dan

*Corresponding author: Jurusan Fisika FMIPA UNSRAT, Jl. Kampus Unsrat, Manado, Indonesia 95115; Email address: juwana1404@gmail.com Published by FMIPA UNSRAT (2018) 
arus dapat dilakukan baik dengan cara alami (pasif) maupun aktif. Metode geolistrik yang sering digunakan salah satunya adalah geolistrik tahanan jenis.Metode geolistrik tahanan jenis dilakukan dengan menginjeksikan arus listrik kedalam permukaan bumi dengan sepasang elektroda arus dan potensial. Pengukuran beda potensial dapat memperkirakan nilai hambatan yang terdapat didalam bumi.

Metode geolistrik tahanan jenis sendiri telah banyak dimanfaatkan oleh beberapa peneliti untuk mengetahui struktur bawah permukaan baik secara lateral maupun vertikal. Sharifi et al., (2014) melakukan penelitian tentang eksplorasi air dari kars dengan menggunakan metode geolistrik konfigurasi Schlumberger VES dan Dipol-dipol didaerah Tepal, Sharood Barat Iran dan menemukan bahwa daerah tersebut cocok dilakukan pengeboran untuk mengakses dan mengekstrak air tanah dari kars. Menggambarkan akuifer air tanah struktur bawah permukaan dengan menggunakan geolistrik konfigurasi Schlumberger di Daklah Oasis, Mesir dapat mengidetifikasi pada struktur bawah permukaan untuk setiap lapisan (Muhamaden, 2016).Wijaya (2015), melakukan penelitian di halaman belakang SCC ITS Surabaya dengan menggunakan metode geolistrik tahanan jenis (Resistivitas) konfigurasi Wenner dan menemukan lapisan air tanah dengan resistivitas yang relatif kecil.Lapisan yang mengandung air tanahtersebut berada pada kedalaman 1,35-1,99 $\mathrm{m}$ dengan resisitivitas $\quad 0,551-2,75 \Omega m$.Munchingami (2012), melakukan survei resistivitas listrik menggunakan konfigurasi Schlumberger untuk penyelidikan air tanah dangkal bawah permukaan guna mengevaluasi formasi basaltik-grreenstone diperkotaan Bawalayo dan dapat didudga lokasi tersebut dapat dijadikan prospeksi air tanah jangka panjang.

Oladunjoye et al. (2013) melakukan evaluasi air tanah dengan metode resistivitas listrik dengan konfigurasi Schlumbereger di daerah Okenugbo, Nigeria hasilnya menunjukan variasi batuan untuk potensi air tanah sangat rendah. Yadav et al., (1997) melakukan penyelidikan air tanah dangkal di India dengan menggunakan konfigurasi Schlumbrger dan pol-dipol. Pemetaaan akuifer air tanah di wilayah kampus Universitas Sam Ratulangi Manado dengan menggunakan metode geolistrik tahanan jenis konfigurasi Schlumbereger menunjukan hanya terdapat sebaran air tanah dangkal dengan kedalam tertentu ( Sulu et al., 2015). Sedana et al. (2015) melakukan pemetaan akuifer air tanah di jalan Ringroad Kelurahan Malendeng dengan menggunakan metode geolistrik tahanan jenis konfigurasi Schlumberger dan ditemukan ada sebaran titik akuifer air tanah pada daerah dekat sungai. Penelitian mengenai pemetaan akuifer air tanah di masjid kampus Universitas Sam Ratulangi dan sekitarnya menggunakan konfigurasi Wenner-Schlumberger dalam metode geolistrik tahanan jenis telah dilakukan dan diperoleh sebaran resistivitas yangkecil yaitu $0,12 \Omega m-0,64 \Omega m$ dengan letak akuifer air tanah pada lintasan 1, 3, 4 dan 5 dengan kedalaman yang berbeda (Saranga et al., 2016). Gijoh (2017), telah melakukan identifikasi akuifer air tanah dengan mnggunakan metode geolistrik tahanan jenis konfigurasi Dipol-dipol di masjid kampus Universitas Sam Ratulangi dan sekitarnya dengan jumlah 5 lintasan, dari ke-5 lintasan tersebut yang terindikasi terdapat akuifer air tanah dengan resistivitas $\rho \leq 7,16 \Omega m$ pada lintasan 1,3 , 4 dan 5.

Penelitian analisis perbandingan konfigurasi pernah dilakukan (Janah, 2014) dengan menggunakan konfigurasi Wenner, Schlumberger dan Dipol-dipol akan tetapi hanya pada skala laboratorium. Berkaitan dengan hal tersebut diperlukan adanya penelitian lagi untuk skala yang lebih luas untuk perbandingan konfigurasi yaitu : Wenner Alfa, Wenner-schlumberger, Dipol-dipol dan Pol-dipol dalam metode geolistrik tahan jenis menggunakan resistivity meter : multichannel and multielectrode resistivity and IP meter simultaneous channel merekMAE X612-EM dalam pendeteksian akuifer air tanah, sehingga akan didapatkan metode yang efesien dan efektif dalam pendeteksian air tanah menggunakan alat tersebut.

\section{Material dan Metode}

Penelitian ini telah dilakukan di lapangan Universitas Sam Ratulangi Manado. Waktu pelaksanaan penelitian dimulai bulan Juni sampai Desember 2017.

Alat yang digunakan dalam penelitian adalah : geolistrik resistivity meter: Multichannel and Multielectrode Resistivity and IP meter simultaneous channel merek MAE X612-EM, Global Postioning system (GPS) Garmin, Meteran (100 m), Laptop Aspire ES 11, Perangkat lunak RES2DINV, Perangkat lunak NotepaddanPerangkat Iunak Google Earth.

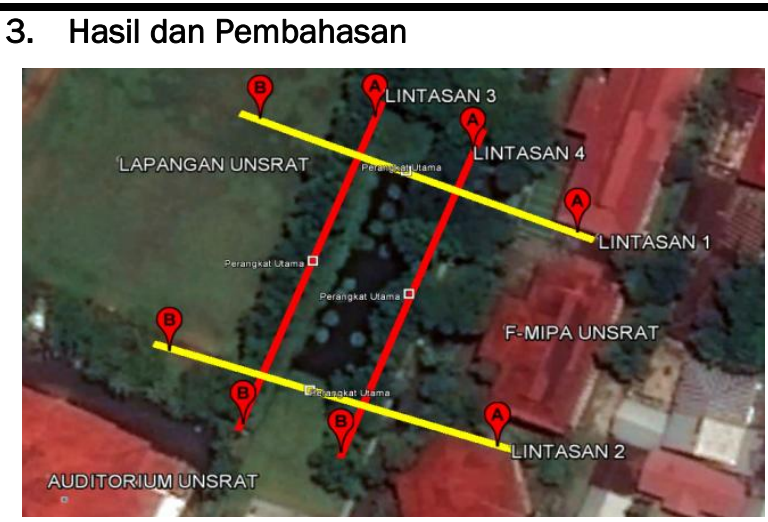

Gambar 1.Lintasan Pengukuran

Gambar 1. Menunjukkan posisi bentangan lintasan yang sebenarnya dengan letak titik koordinat yang berbeda-beda. Lintasan satu dan lintasan dua bentangan kabel $A$ dan kabel $B$ terbentang dari Timur Tenggara ke Barat-Barat Laut. 
Lintasan tiga dan lintasan empat bentangan kabel Adan kabel B terbentang dari Utara Timur Laut ke Selatan Barat Daya.

\subsection{Hasil Pengolahan Data Tampang Lintang Resistivitas Lintasan 1}

Data hasil pengukuran dalam ekstensi DAT. diolah dengan menggunakan perangkat lunak (softwere) RES2DINV dan menghasilkan gambar tampang lintang resistivitas 2D bawah permukaan tanah. Proses inversi data pengukuran dimasukkan faktor topografi sesuai dengan kondisi lokasi berdasarkan GPS (Global Postioning system). Model tampang lintang memiliki nilai resistivitas yang ditunjukkan oleh warna-warna, dengan sumbu vertikal menunjukkan kedalaman (elevasi) dalam meter dan sumbu horizontal merupakan posisi elektroda dalam meter.

\subsubsection{Konfigurasi Wenner Alfa}

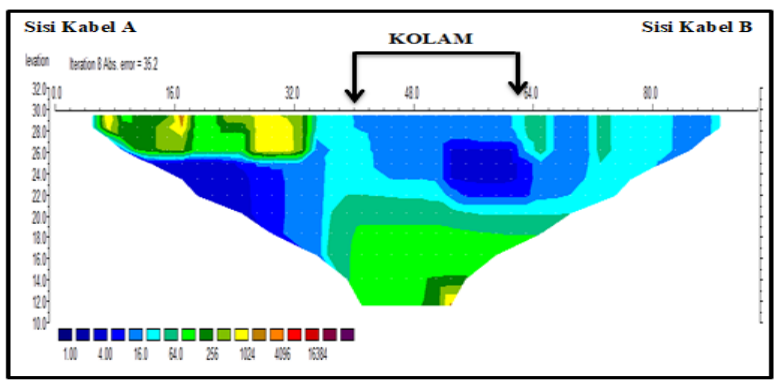

Gambar 2.Resistivitas konfigurasi Wenner Alfa dengan topografi

Berdasarkan tabel tabel nilai resistivitas (Loke, 2000) tampang lintang yang ditunjukkan pada Gambar 2.memiliki sebaran akuifer dengan nilai resistivitas rendah $\leq 16 \Omega \mathrm{m}$. Pada meter ke-10 sampai meter ke-36 terdapat akuifer dengan kedalaman $\geq 10,5$ meter. Pada meter ke-40 sampai meter ke-61 dan pada meter ke-67 sampai meter ke-71 terdapat akuifer dengan kedalaman 1 meter sampai 9 meter dari permukaan tanah. Akuifer juga terdapat pada meter ke-83 sampai meter ke-88 dengan kedalaman 5 meter.

\subsubsection{Konfigurasi Wenner-Schlumberger}

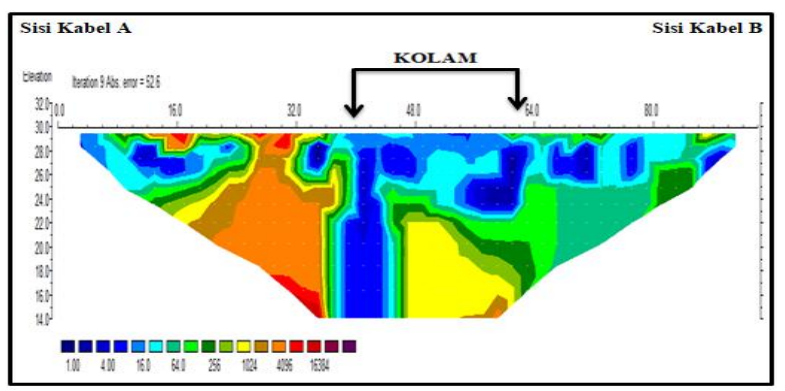

Gambar 3.Resistivitas konfigurasi WennerSchlumberger dengan topografi

Gambar 3. Menunjukkan bahwa terdapat sebaran akuifer air tanah dengan harga resistivitas pengukuran yang berkisar antara $0 \Omega m-16384 \Omega m$ dengan kedalaman 16 meter. Lapiasan yang memiliki nilai resistivitas $\leq 16 \Omega \mathrm{m}$ yang diduga sebagai akuifer terletak diantara meter ke-3 dan meter ke-24 dengan kedalaman 1 meter sampai 4,5meter. Sepanjang bentangan antara meter ke-33 sampai meter ke-64 terdapat akuifer dengan kedalaman 1 meter sampai 16 meter. Pada meter ke-66 sampai meter ke-72 dan pada meter ke-75 samapai meter ke 79 terdapat akuifer dengan kedalaman 4 meter. Akuifer juga terdapat pada meter ke-86 dan meter ke-90 denga kedalaman $\geq 2$ meter.

\subsubsection{Konfigurasi Dipol-dipol}

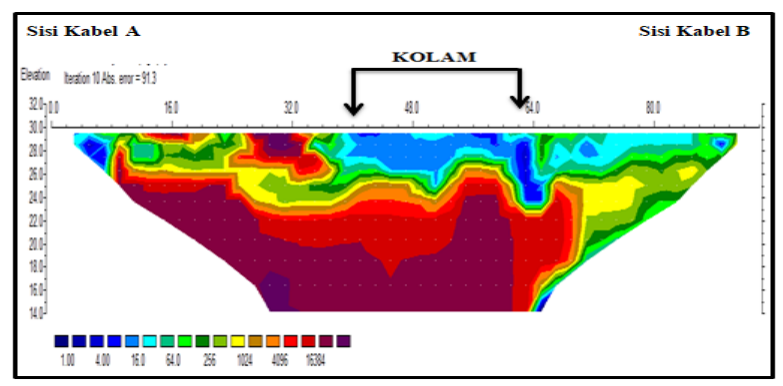

Gambar 4.Resistivitas konfigurasi Dipol-dipol dengan topografi

Gambar 4. Menunjukan menunjukkan harga resistivitas $\leq 16 \Omega \mathrm{m}$ yang merupakan akuifer berada dekat permukaan antara meter ke-3 sampai meter ke-10 dengan kedalaman $\geq 1$ meter. Pada meter ke-39 dan meter 65 terdapat akuifer dengan kedalaman 4 meter sampai 6.5 meter. Pada meter ke-70 sampai meter ke-72 dan meter ke-88 samapai meter ke-90 juga terdapat lapisan pembawah air (akuifer) degan kedalaman 1 meter.

\subsubsection{Konfigurasi Pol-dipol}

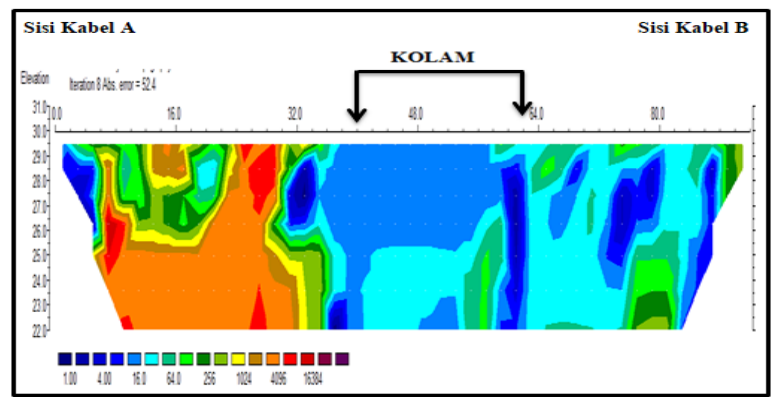

Gambar 5.Resistivitas konfigurasi Pol-dipol dengan topografi

Panjang bentangan pengukuran lintasan 1 konfigurasi pol-dipol 96 meter dengan spasi elektroda 2 meter dan jumlah elektroda 48 yang memberikan 369 data (Lampiran 13). Hasil pengolahan dengan menggunakkan perangkat lunak RES2DINV yang diinversi menghasilkan tampang lintang resistivitas 2D yang berkisar antara0 $\Omega \mathrm{m}$ sampai $16384 \Omega \mathrm{m}$ dengan kedalaman pengukuran 8 meter.

Sepanjang lintasan yang dimulai dari meter ke-1 sampai meter ke-8 yang berada dekat permukaan merupakan lapisan akuifer dengan kedalaman 4 meter memiliki nilai resistivitas $\leq 16 \Omega \mathrm{m}$. Akuifer berada pada meter ke-30 sampai meter ke-62 dengan kedalaman 1 meter sampai 8 meter yang 
miliki resistivitas $\leq 16 \Omega \mathrm{m}$. Bidang lemah yang merupakan akuifer dengan nilai resistivitas $\leq$ $16 \Omega \mathrm{m}$ terdapat pada meter ke-64 sampai meter ke70 , pada meter ke-71 sampai meter ke-80 dan pada meter ke-82 sampai meter ke-90 dengan kedalaman 5 meter sampai 7 meter.

\subsection{Analisis Perbandingan Konfigurasi Wenner Alfa, Wenner-Schlumberger, Dipol-dipol dan Pol-dipol dalam Mendeteksi Keberadaan Air Tanah}

Perbandingan 4 konfigurasi yaitu Wenner Alfa, Wenner-Schlumberger, Dipol-dipol dan Pol-dipol dalam mendeteksi keberadaan air tanah dengan data posisi elektroda dan kedalaman akuifer ditunjukan pada Tabel1.

\section{Tabel 1. Perbandingan Konfigurasi}

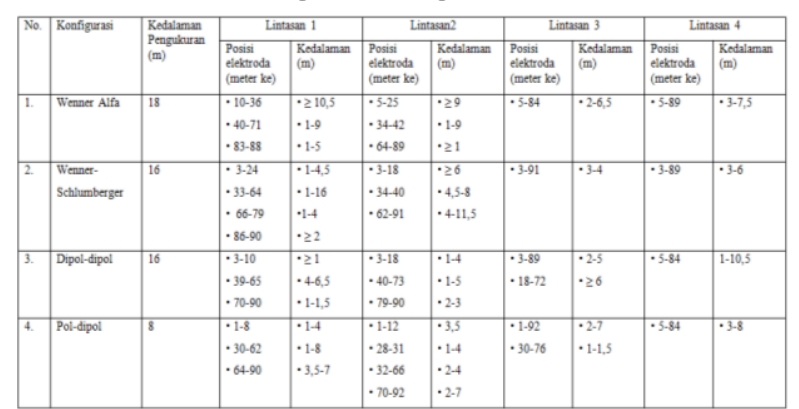

Berdasarkan Tabel1.Terlihat bahwa adanya kesamaan keberadaan akuifer dengan nilai resistivitas $\leq 16 \Omega m$ pada posisi elektroda yang bersesuaian terutama yang terdapat di daerah kolam. Keempat konfigurasi dapat digunakan untuk mendeteksi keberadaan air tanah akan tetapi dari segi hasil, konfigurasi Wenner-Schlumberger dan Dipol-dipol terlihat lebih baik struktur perlapisannya ( Loke., 2000 ; Dahlin and Bing., 2003).

Tabel 2. Karakteristik konfigurasi pada resistivitymeter:Multichannel and Multielectrode Resistivity and IP meter simultaneous channel merek MEA X612-EM

\begin{tabular}{|r|l|c|l|c|}
\hline No. & Konfigurasi & $\begin{array}{l}\text { Jumlah } \\
\text { Data }\end{array}$ & $\begin{array}{l}\text { Waktu } \\
\text { Eksekusi } \\
\text { (menit) }\end{array}$ & $\begin{array}{l}\text { Jumlah Titik } \\
\text { sekali Eksekusi } \\
\text { (titik) }\end{array}$ \\
\hline 1 & Wenner Alfa & 184 & 31 & 1 \\
\hline & $\begin{array}{l}\text { Wenner- } \\
\text { Schlumberger }\end{array}$ & 576 & 91 & 1 \\
\hline 3 & Dipol-dipol & 609 & 24 & 5 \\
\hline 4 & Pol-dipol & 369 & 7 & 9 \\
\hline
\end{tabular}

Konfigurasi Wenner Alfa kedalaman penetrasi arus sampai 18 meter sedangkan Pol-dipol penetrasinya hanya 8 meter.sehinga dilihat dari terdapatnya air tanah dan kedalaman penetrasi, Konfigurasi Wenner-Schlumberger dan Dipol-dipol itu lebih baik. Hasil penggambaran lapisan batuan berhubungan erat dengan jumlah data yang didapatkan dari pengukuran untuk luasan yang sama, efesiensi pengukuran berhubungan dengan waktu akuisisi data dan jumlah data per satuan eksekusi. Kondisi ini dapat dilihat pada table2.

Berdasarkan table2.Menunjukkan bahwa jumlah data Wenner-Schlumberger dan Dipol-dipol hampir sama yaitu 576 dan 609. Konfigurasi Poldipol dan Wenner Alfa lebih sedikit yaitu 369 dan 184, sehingga konfigurasi Wenner-Schlumberger dan Dipol-dipol mempunyai gambaran tampang lintang yang lebih ditel dibandingkan konfigirasi Wenner Alfa dan Pol-dipol. Dilihat dari waktu eksekusi konfigurasi Pol-dipol hanya memerlukan waktu sangat singkat yaitu 7 menit, untuk konfigurasi Wenner Alfa dan Dipol-dipol membutuhkan waktu eksekusi lebih lama yaitu 31 menit dan 24 menit. Sedangkan konfigurasi Wenner-Schlumberger membutuhkan waktu eksekusi sangat lama yaitu 91 menit.

Berdasarkan analisis didapat bahwa konfigurasi yang paling efisien dan efektif dalam pendeteksian keberadaan air tanah adalah Konfigurasi Dipol-dipol dengan karakteristik konfigurasi adalah wakru eksekusi 24 menit, jumlah data 609 buah, kedalaman penetrasi 16 meter dan jumlaj data pereksekusi 5 titik.

\section{Kesimpulan}

Telah dilakukan penelitian untuk mencari konfigurasi yang tepat dalam eksplorasi sumber daya air (air tanah) dengan metode geolistrik tahanan jenis dengan konfigurasi Wenner Alfa, Wenner-Schlumberger, Dipol-dipol dan Pol-dipol menggunakan Resistivitymeter (multichannel and multielectrode resistivity and IP meter simultaneous channel merek MAE X612-EM), dengan spasi 2 meter dan jumlah elektroda 48 buah. Didapatkan hasil konfigurasi Dipol-dipol adalah konfigurasi yang paling efektif dan efisien untuk mendeteksi keberadaan air tanah.

Karakteristik konfigurasi Dipol-dipol dalam pendeteksian air tanah adalah waktu eksekusi 24 menit, jumlah data 609 buah, kedalaman penetrasi 16 meter dan jumlah data pereksekusi 5 titik.

\section{Daftar Pustaka}

Dahlin T., dan Bing Z. 2003. A Numerical Comparison Of 2D Resistivity Imaging with Ten Electroda Arrays. Department Of Engineering Geology University Lund, Sweden.

Enggarwati, D.A., Adi S., dan Dadan D. W. 2014. Pendugaan Akuifer serta Pola Alirannya dengan Metode Geolistrik Daerah Pondok Pesantren Gontor 11 Solok-Sumatera Barat. Physics Student Journal. 2(1): 549553.

Gijoh, O. T. 2017. Identifikasi Akuifer Air Tanah Di Masjid Kampu Universitas Sam Ratulangi dan Sekitarnya dengan Menggunakan Metode Geolistrik Tahanan Jenis Konfigurasi Dipoldipol. Jurusan Fisika F-MIPA UNSRAT, Manado.

Janah, S. R. 2014. Analisis Perbandingan Elektroda untuk Identifikasi Keberadaan Air pada Skala Laboratorium dengan Metode Geolistrik Resistivitas. Jurusan Fisika F-ST UINSK, Yogyakarta. 
Loke, M. H. 2000. Electrical imaging surveys for environmental and engineering studies. A Practical Guide to 2-D and 3-D Surveys.University of Birminfham, Birmingham.

Mohamaden, M. I. I. 2016. Delineating Groundwater Aquifer and Subsurface Structures by Using Geoelectrical Data: Case Study (Dakhla Oasis, Egypt). NRIAG Journal of Astronomy and Geophysics. 5(1): 247-253.

Muchingami, I., Hlatywayo D. J., Nel J. M., and Chuma C. (2012).Electrical Resistivity Survey for Groundwater Investigations and Shallow Subsurface Evaluation of the Basaltic-Greenstone Formation of the Urban Bulawayo Aquifer. Physics and Chemistry of the Earth, Parts A/B/C.50(1): 44-51.

Oladunjoye, H. T., Odunaike R. K., Ogunsola, P., and Olaleye O. A. (2013). Evaluation of Groundwater Potential Using Electrical Resistivity Method in Okenugbo Area, AgoIwoye, Southwestern, Nigeria. International Journal of Engineering and Applied Sciences. 4(5).

Saranga, H. T., As'ari, dan Seni H. J. T. 2016. Deteksi Air Tanah Menggunakan Metode Geolistrik Resistivitas Konfigurasi WnnerSchlumbereger Di Masjid Kampus Universitas Sam Rayulangi dan
Sekitarnya.Jurnal

Online.5(2): 70-75.

Sedana, D., As'ari, dan Adey T. (2015). Pemetaan Akifer Air Tanah Di Jalan Ringroad Kelurahan Malendeng dengan Menggunakan Metode Geolistrik Tahanan Jenis. Jurnal IImiah Sains. 15(1): 33-37.

Sharifi, F., A. R. Arab-Amiri, and A. Kamkar-Rouhani., 20214. Karstic Water Exploration Using the Schlumberger VES and DipoledipoleResistivity Profiling Surveys in the Tepal Area, West of Shahrood, Iran. Journal of Mining and Environment, 5(1): 1-12.

Sulu S. S., As'ari dan Seni H. J. T., (2015). Pemetaan Akuifer Air Tanah Di Wilayah Kampus Unsrat Manado dengan Menggunakan Metode Geolistrik Tahanan Jenis. Juernal IImiah Sains. 15(1): 20-26.

Wijaya, A. S. (2015). Aplikasi Metode Geolistrik Resistivitas Konfigurasi Wenner Untuk Menentukan Struktur Tanah di Halaman Belakang SCC ITS Surabaya.Jurnal Fisika Indonesia, 119(55): 1-5.

Yadav, G. S., Singh, P. N., \& Srivastava, K. M. (1997).Fast method of resistivity sounding for shallow groundwater investigations. Journal of applied geophysics, 37(1), 45-52. 